\title{
How Does The "Flipped Classroom Model” Impact On Student Motivation And Academic Achievement In A Chemistry Classroom?
}

\author{
Nicole Sookoo-Singh', Laila N. Boisselle ${ }^{2 *}$ \\ ${ }^{1}$ School of Education, Faculty of Humanities and Education, The University of the West Indies, Trinidad and Tobago, ${ }^{2}$ Division of Education, Higher \\ Colleges of Technology, Ras al Khaimah Women's Campus, United Arab Emirates
}

*Corresponding Author: boissellelaila@gmail.com

\section{ABSTRACT}

This action research was completed as a module on an in-service teacher education program and addressed form four (year 10, students aged 14-15 years old) students' demotivation to study chemistry on the Caribbean island of Trinidad. My students often find chemistry challenging, and I suspect that teacher-centered methods probably contribute to their experience. The flipped classroom model was selected based on a review of the literature which identified it as a student-centered method with potential to impact both motivation and academic achievement. The research considered the flipped classroom's impact on students' motivation, academic performance, and perceptions of the intervention itself. The study was conducted over 4 weeks, and lessons were delivered asynchronously through the use of various Information Communication Technology resources such as email, websites, powerpoint presentations, and videos. Both qualitative and quantitative data were collected. Within the limitations of this study, academic achievement was not significantly impacted; student motivation was positively and significantly affected; and most students' perception of the intervention was favorable though some indicated a preference for in-class lectures. Findings suggest further research into the utility of a blended method of synchronous and asynchronous lectures.

KEY WORDS: flipped classroom; motivation; academic achievement; Trinidad/Caribbean; chemistry education; science education

\section{INTRODUCTION}

\section{Background}

$\mathbf{T}$ o improve students' motivation and possible subsequent academic achievement in chemistry, this study investigated a move from a teacher-centered, lecture-based model to an active, and student-centered model of instruction (flipped classroom). The study was conducted at a denominational, single-sex female school on the Caribbean Island of Trinidad in the twin-Island state of Trinidad and Tobago. The school is classified nationally and within the Caribbean region as a highperforming one. Students are goal-oriented, come from a range of socioeconomic backgrounds, and the activities of the school are strongly supported by the parent base. Even so, I have found my year 10/form four students demotivated to study chemistry.

The vast content and depth of the multifaceted subject of chemistry can present a challenge to many students. Students are motivated to learn when they find pedagogical activities purposeful, rewarding, useful, and significant enough to be encouraged to work for the benefits that may be derived from the educational objectives of these activities (Brophy, 1998). According to a study conducted by Cavas (2011), student motivation levels influence their attitude toward science and their achievement in science. Findings supported the view that students who have high motivation to learn science are more successful in science learning. Motivation is, therefore, a vital educational variable promoting both new learning and performance of previously learned skills, strategies, and behaviors (Barlia, 1999). Moreover, it has been found that science achievement has been strongly linked to motivation (Singh et al., 2002; Britner and Pajares, 2006), and in a study conducted by Akbas and Kaan (2007) on high school, chemsitry students revealed that motivation can be used as a significant predictor of academic achievement.

I have realized that many of my students in the form four are unmotivated to study chemistry as they find it to be a very challenging subject. At the institution where the study occurred there is a very competitive learning environment and expectation that the historic, high academic performance of the school will be maintained. This expectation coupled with time limitations to complete the syllabus caused a very teacher-centered model of delivery to be employed. In this model students generally assume a passive role which seems to demotivate them. It also leaves little time to engage students' in active scientific type discovery activities, particularly those that allow them to independently apply theoretical knowledge and so allow students to become more involved participants in their own learning.

Compared to those in traditional teacher-centered classes, students in student-centered environments are more involved in their own learning and show improved retention, and better conceptual understanding of the learned material (Sezer, 2010). There has been a worldwide move toward student-centered 
learning and a departure from the role of teachers as a "sage on the stage" who imparts their wisdom during class time (King, 1993). Student-centered learning embraces a constructivist model of learning as it presents learning as an active process in which teachers are facilitators who guide their students to independently shape personal conceptual development (Rhodes and Bellamy, 1999). Student-centered learning, as an active process, provides opportunities for students to meaningfully talk, listen, write, read, and reflect on the content, ideas, issues, and concerns of an academic subject (Meyers and Jones, 1993). Switching to a more student-centered approach might improve students' conceptual grasp of content by giving them significant opportunities to become motivated, independent/active learners who are responsible for creating their own knowledge.

\section{Problem Statement}

My form four students have low motivation to study chemistry due to their perception that the subject is challenging. This may be compounded by the predominant use of teacher-centered methods which do not allow students to be active participants in their own learning. These factors have had a negative impact on their academic performance.

\section{Purpose Statement}

The study focuses on the impact of the flipped classroom model on form four students' motivation toward studying chemistry and by extension their academic performance. Students' perception of the flipped classroom model was also investigated.

\section{Research Questions}

1. What is the impact of the flipped classroom model on students' motivation during a unit of chemical instruction?

2. What is the impact of the flipped classroom model on the academic performance of students on a unit of work in chemical instruction?

3. What are students' perceptions of the intervention (flipped classroom)?.

\section{Significance of the Study}

It is hoped that this action research may assist the students involved in developing greater motivation in chemistry and lead to improvements in their academic achievement.

As a chemistry teacher, the findings of this study can assist me in developing a new repertoire of student-centered strategies. Findings from this research also have the potential to impact on the methods of teaching currently employed in my department and by extension my school and the larger teaching community.

\section{LITERATURE REVIEW}

Motivation is a powerful contributor to the behavior of students and determines the strength and stability of that behavior (Akbaş and Kaan, 2007). Motivation has been defined as "cognitive, emotional, and behavioral indicators of student investment in an attachment to education" (Tucker et al., 2002. p. 72).
Motivation is a major component of a student's self-efficacy. According to Bandura (1997), self-efficacy beliefs affect academic performance by influencing a number of behavioral and psychological processes, where if a student believes in their ability to perform a task, there is a higher likelihood that they will. Several studies have confirmed that the connection between a student's self-efficacy in their academic capabilities is related to their academic motivation and performance in subject areas that include science, mathematics, and language arts (Britner and Pajares, 2001; Shell et al., 1995). Hence, if students are motivated, they are more likely to participate in the learning process, exert greater effort, and these can positively influence academic achievement.

Factors positively influencing students' motivation to learn chemistry include teaching approaches, educational tools, non-formal educational materials, and activities (Salta and Koulougliotis, 2012). There are myriad teaching approaches and they can be put into two broad categories: teachercentered and student-centered (Prosser \& Trigwell, 1998). There has also been a noted shift from teacher-centred to more student-centered strategies (Jonassen, 1993; Ramsden, 1992). Popular student-centered teaching approaches involve students in their own learning and include laboratory instruction, interdisciplinary approaches, inquiry based approaches and constructivist methods. This study focuses on the use of a constructivist student-centered strategy which is the flipped classroom model.

The flipped classroom uses educational technology tools and active learning within a student-centered environment to positively influence the learning by moving instruction out of the classroom (O'Neil, Kelly and Bone, 2012). In a flipped classroom students' access instruction that formerly occurred at school from home using Information Communication Technology (ICT) tools, and use class time to work on applying concepts (Tucker, 2012). The flipped classroom uses educational technology and active learning to shift instruction out of the classroom and allows the independent creation of work as opposed to traditional models of the lecture classroom (O'Neil, Kelly and Bone, 2012). The great diversity of ICT educational tools available has provided opportunities for teachers to make learning interactive and more accessible to students. The value of technology as a learning tool has been researched extensively, but often with inconclusive, results as outcomes are difficult to measure. Even so, studies have identified technology as a factor which leads to the enhancement of problem-solving, conceptual development, and critical thinking (Culp et al., 1999; Sandholtz et al., 1997).

The flipped classroom has the potential to motivate students (Usher and Kober, 2012). Moreover, the flexibility of the flipped classroom allows the pace of the lessons to be matched to students' learning as they can view the lesson at their own comfort level and review, pause, and fast forward as is needed. The flipped classroom's reliance on ICTs is appealing to students as seen by technology's potential to motivate students 
to learn mathematics and science (Nugent et al., 2006). Indeed the flipped classroom is a student-centered method and may have the capacity to impact student motivation and academic achievement with its potential to:

- Increase student motivation by focusing less on content delivery in the classroom: students then have more time during class to apply and practice concepts, and to carry out activities and exploration(Johnson, 2013).

- Allow students to actively participate in learning and engage with material rather than passively listening to a lecture (Knewton, 2012). This can improve selfmotivation.

- Increase student performance (Kirch, 2012; Fulton, 2012; Green, 2012).

- Meet students on their own technological level (Franciszkowicz, 2008).

In summary, the use of ICTs as education technology provides students with flexibility in the way they access their learning. Roach (2006) found that students prefer to access learning material asynchronously because they can choose to do so when it fits their schedules and lifestyle. The flipped classroom is one method which does this in a student-centered way by allowing students to actively construct their own knowledge as they engage with learning materials in an ICT environment. Hands-on learning activities such as these have been shown to improve children's science learning, achievement and their attitudes toward science, increase science skill proficiency and language development, and to encourage creativity (Haury and Rillero, 1994).

\section{METHODOLOGY}

Qualitative and quantitative data were accumulated through the use of a mixed methods approach. Creswell and Clark (2007) described the mixed methods research design as one which "focuses on collecting, analyzing, and mixing both quantitative and qualitative data in a single study" to "provide a better understanding of research problems than either approach alone" (p. 5).

\section{Research Question One}

Quantitative data were collected through the administration of a Likert scale questionnaire to measure motivation (Glynn et al., 2011) pre- and post- intervention. This questionnaire has proven useful in providing "a comprehensive understanding of students' motivation to learn science" (Glynn et al., 2011. p. 15). The questionnaire was administered before and after the intervention (flipped classroom) was used to teach a unit of work on chemical reactions. The questionnaire was composed of 25 questions with possible responses ranging from never to "always" which were scored using a rating scale of one to five (one corresponded to never and five to always). All of the questions were positively stated so that the questionnaire had a maximum possible score of 125 indicating high motivation and a minimum possible score of 25 which would indicate low motivation.

The pre- and post-intervention results from the questionnaires were analyzed using the t-test, Kolmogorov-Smirnov test, and the Wilcoxon test to determine if there had been a change in students' motivation levels over the course of the intervention.

\section{Research Question Two}

Quantitative data were collected through the administration of a summative unit test post the use of the intervention (Table of Specifications, Table 1). This was compared with a base/pre-test score of the previous end of term/semester examination results.

This research question employed a base score/pre-test and post-test design. The base score approach used the end of term mark for the students' performance in chemistry previous to the semester/term in which the study was carried out. This approach was selected based on the limitations to the use of a "true" pre-test/post-test research design which would have administered the same instrument to measure student performance before and after the intervention (as happened in research question one).

It was not possible to use the true pre-test approach as this would have generated skewed results not representative of the students' academic ability. This is known as the testing effect and is a flaw

\begin{tabular}{|c|c|c|c|c|c|c|c|c|c|c|c|c|c|c|c|c|c|}
\hline \multirow{4}{*}{$\begin{array}{l}\text { Bloom's } \\
\text { Classification }\end{array}$} & \multicolumn{16}{|c|}{ Content areas } & \multirow[t]{4}{*}{ Tota } \\
\hline & \multicolumn{2}{|c|}{$\begin{array}{l}\text { Chemical } \\
\text { Reactions }\end{array}$} & \multicolumn{2}{|c|}{$\begin{array}{l}\text { Determine } \\
\text { rate }\end{array}$} & \multicolumn{2}{|c|}{$\begin{array}{c}\text { Collision } \\
\text { theory }\end{array}$} & \multicolumn{2}{|c|}{$\begin{array}{c}\text { Effect of } \\
\text { temperature } \\
\text { on the rate of } \\
\text { reaction }\end{array}$} & \multicolumn{2}{|c|}{$\begin{array}{c}\text { Effect of } \\
\text { concentration } \\
\text { on the rate of } \\
\text { reaction }\end{array}$} & \multicolumn{2}{|c|}{$\begin{array}{l}\text { Effect of } \\
\text { pressure } \\
\text { on the rate } \\
\text { of reaction }\end{array}$} & \multicolumn{2}{|c|}{$\begin{array}{c}\text { Effect of } \\
\text { surface area } \\
\text { on the rate of } \\
\text { reaction }\end{array}$} & \multicolumn{2}{|c|}{$\begin{array}{l}\text { Effect of } \\
\text { catalyst on } \\
\text { the rate of } \\
\text { reaction }\end{array}$} & \\
\hline & \multicolumn{16}{|c|}{ Objectives (see Table 2) } & \\
\hline & 1 & 2 & 1 & 2 & 1 & 2 & 1 & 2 & 1 & 2 & 1 & 2 & 1 & 2 & 1 & 2 & \\
\hline Knowledge & 5 & & 10 & & 5 & 10 & & & & & 5 & & & & 5 & 5 & 45 \\
\hline \multicolumn{18}{|l|}{ Comprehension } \\
\hline Application & & & & & & & & 10 & & 7 & & 6 & & 7 & & & 30 \\
\hline Analysis & & 5 & & 5 & & & 5 & & 5 & & & & 5 & & & & 25 \\
\hline Total & & & & & & & & & & & & & & & & & 100 \\
\hline
\end{tabular}


in the typical pre-test/post-test design (Altermatt, 2014). This question looks at the change in students' academic scores as an indication of how well they have learned the content matter of the unit. The students had not been previously taught the chemistry content of the unit and were not able to complete a pre-test on such material. It is possible too that by completing a true pretest that the student may have been able to recall the questions and therefore any improvement in scores may not have been influenced by the intervention. For a true pre-test, the students would have needed to be taught the material without the use of the intervention. This would then bias the intervention as the students would have been sensitized to the material. A control group might be thought as a useful comparative measure in the absence of a true pre-test. However, in educational research a control group is considered to be unethical as it can deprive a group of students from the benefit of a successful intervention (Shadish, Cook, \& Campbell, 2002). On the other hand, using a control group can possibly put the test group at risk if the intervention proves harmful or fails. . The one group base score/ pre-test post-test design was therefore employed.

The base score represents an assessment of students' long-term learning over a 3 months term/semester. Moreover, the end of term examination used as the base score represents student performance over several units of chemistry instruction and can be considered a valid representation of the students' average performance without the use of the intervention. Hence, this end of term/semester examination score was considered to be a stable base score for students. The use of a pre-test score that is stable over a long period of time has been proposed as a viable alternative in pre/post-test designs (Slavin, 2007).

The post-test scores came from a summative assessment administered on completion of the unit. These scores were compared to the base/pre-test scores and statistical tests, namely t-test, Kolmogorov-Smirnov test, and Wilcoxon signed-rank test, were carried out to determine if there was any significant change in the students' academic performance.

\section{Research Question Three}

Qualitative data were collected in the form of journals written at the end of the first and last teaching sessions of the study. These journals were analyzed to detect any patterns based on students' perception of the intervention using coding based on the constant comparative analysis technique.

\section{Description of the Sample}

The sample consisted of 27 females form four (year 10/1415 years old) chemistry students. At the secondary school in which the study occurred students are allowed to choose a combination of subjects from possible groupings named after their core patronage: Science, Business, and Modern Studies. Regardless of their core patronage, all students were required to study a natural science subject. However, final placement in any subject group is a combination of personal choice, academic ability, and constraints due to the physical and teaching infrastructure available. Some students then may be placed in a core patronage group of subjects not by choice or ability but due to space limitations. Students in the group under study are made up of students from across all the patronage groups. This means that most of them were not pursuing chemistry as a personal choice but more so as a mandate.

\section{Limits and Delimits of the Study}

Sample size and the method of selection of the sample were two major limitations of this study. The class selection process was a type of non-probability sampling called convenience sampling. The elements comprising a convenient sample are selected from the target population on the basis of their accessibility or convenience to the researcher (Ross, 2005). This method introduces the assumption that the findings would be no different if the sampling method was random. However, there may be substantial bias in the sample as extraneous variables may have affected the results; therefore, the results obtained are valid only for the class studied. As a result of the small sample size, generalizations cannot be made for larger populations, and this also limits the findings of this study.

The absence of control group gives the study a quasi-experimental design. This means that any results obtained may be influenced by one or more factors external to the intervention (Slavin, 2007). External factors could encompass a variety of factors such as student attentiveness based on the time the lesson is taught, as well as environmental factors such as setting or even temperature. This method is, however, still justified in its use as it can be implemented when ethical considerations are important (Shadish et al., 2002) and these conditions have been discussed previously.

The study occurred over eight, one hour long lessons. This means that the long-term effects of the strategies employed in this study could not be determined. This study was conducted in a school which is high achieving and also single-sex (female). This limited the validity of the study as this homogenous population curtails applicability to a more heterogeneous population.

The flipped classroom model also depended heavily on students using the intervention at home to complete their lectures, and there was no way to confirm that they did so before the classroom follow-up sessions which relied on such completion. There was also no way to predict the functionality of the technology for each student, and some students did experience technical difficulties in the use of their home computers or internet connection when using the instructional materials.

Another important limitation was apparent in the measurement of students' motivation in the form of the completion of student journals used to collect qualitative data for research question three. There may have been biases in the completion of the qualitative instruments by the students. This may be due to students not responding based on genuine outcomes but based on what they believe the teacher wanted to hear or based on negative perceptions of the teacher.

\section{Research Procedure}

The study spanned a 6-week period or 8, 1-h sessions. This intervention was based on the completion of online lectures 
at home and the completion of hands-on activities and assigned work based on those lectures, in the classroom. Before the commencement of the study, consent letters were sent to guardians/parents of the students seeking their wards' participation in the study. Permission to conduct the study was also confirmed by the administration of the school.

Before the start of the unit, a Likert scale questionnaire was administered to measure student motivation (Glynn et al., 2011) for research question one.

As research question three used students' journals to collect data, it was necessary to conduct a session on journal writing before the start of the study, as students would not have been

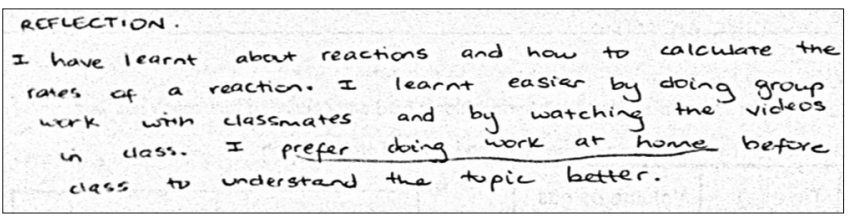

Figure 1: Student journal sample 1

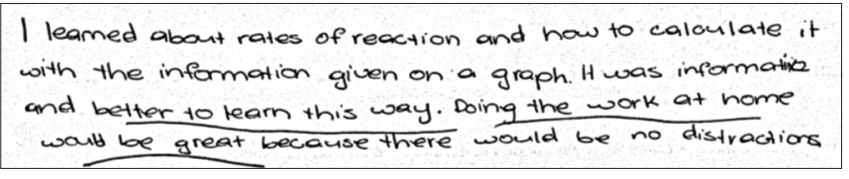

Figure 2: Student journal sample 2 pre-exposed to this form of assessment. At the end of the first and last sessions of the unit of work, students completed a journal entry about their perceptions of the flipped classroom (Figures 1 and 2 for representative examples).

The intervention was done during a unit on the rates of chemical reactions. All topics were taught using the flipped classroom model. Lectures were conducted outside of the classroom asynchronously through the use of a variety of computer-based forms. These included the use of videos, pictures, lecture notes, and other directed activities from the internet, Table 2. On completion of the unit of work the summative assessment for research question two and the Likert scale questionnaire for research question, one was also administered. These were used as components of the quantitative data collected.

\section{Data Analysis and Findings \\ Research question one \\ What is the impact of "the flipped classroom" model on student motivation during a unit on rates of chemical reactions?}

The Likert scale questionnaire administered to students measured motivation to learn science. The questionnaire was scored using a coding system as follows:

1 = "Never"; 2 = "Rarely"; 3 = "Sometimes"; 4 = "Usually"; $5=$ "Always".

The questionnaire consisted of 25 questions making it possible to score a minimum score of 25 and a maximum score of 125 .

\begin{tabular}{|c|c|c|}
\hline Lesson & Specific objectives & How/why intervention was used to teach objectives? \\
\hline Chemical reactions & $\begin{array}{l}\text { Identify different types of chemical reaction. } \\
\text { Write chemical equations for typical chemical reactions } \\
\text { predicting the products. }\end{array}$ & $\begin{array}{l}\text { Weebly site used to deliver a lesson to students } \\
\text { asynchronously } \\
\text { Video utilized }\end{array}$ \\
\hline Determining rate & $\begin{array}{l}\text { Explain the meaning of the term rate of reaction. } \\
\text { Use data, graphs, and equations to calculate reaction } \\
\text { rates. }\end{array}$ & $\begin{array}{l}\text { PowerPoint given to students and posted on Weebly site } \\
\text { for asynchronous use } \\
\text { Animations and pictures utilized }\end{array}$ \\
\hline Collision theory & $\begin{array}{l}\text { Define activation energy. } \\
\text { Describe why reactions occur using the collision theory. }\end{array}$ & $\begin{array}{l}\text { YouTube video, pictures, and PowerPoint emailed for } \\
\text { asynchronous use }\end{array}$ \\
\hline $\begin{array}{l}\text { Effect of temperature on the rate } \\
\text { of reaction }\end{array}$ & $\begin{array}{l}\text { Investigate the effect of changing temperature on the } \\
\text { rate of reaction. } \\
\text { Explain the effect of temperature on the rate using the }\end{array}$ & $\begin{array}{l}\text { Students provided with videos, PowerPoint, and } \\
\text { instruction sheet to use at home through email for } \\
\text { asynchronous use. }\end{array}$ \\
\hline
\end{tabular}

Effect of concentration on rate of Investigate the effect of changing concentration on the reaction

Effect of pressure on the rate of reaction

Effect of surface area on the rate of reaction

Effect of catalyst on rate of reaction rate of reaction.

Explain the effect of concentration on the rate using the collision theory.

Describe the effect of changing pressure on the rate of reaction.

Explain the effect of pressure on the rate using the collision theory.

Investigate the effect of surface areas on reactions rates.

Explain in terms of collisions why surface area changes the rate of reaction.

Describe the effect of catalysts on decomposition of hydrogen peroxide

Explain what catalysts are what they do and the benefits associated with their use.
Students provided with video link to experiment PowerPoint and Animation on collision theory

All the above facilitate the asynchronous use

Students provided with a link to wiki site and video on pressure and rate of reaction for asynchronous use

Simulated lab link provided.

Animations to relate collision theory to the surface area All the above facilitate the asynchronous use Video used to show catalytic decomposition of $\mathrm{H}_{2} \mathrm{O}_{2}$ PowerPoint used to explain what are catalyst

Video used to summarize and consolidate

All the above facilitate the asynchronous use 
A minimum score represents low motivation, and a maximum score represents high motivation. Total scores were calculated for the same questionnaire administered pre- and post-intervention. Descriptive statistics (Table 3), namely mean, standard deviation, range, minimum and maximum, and skewness, were

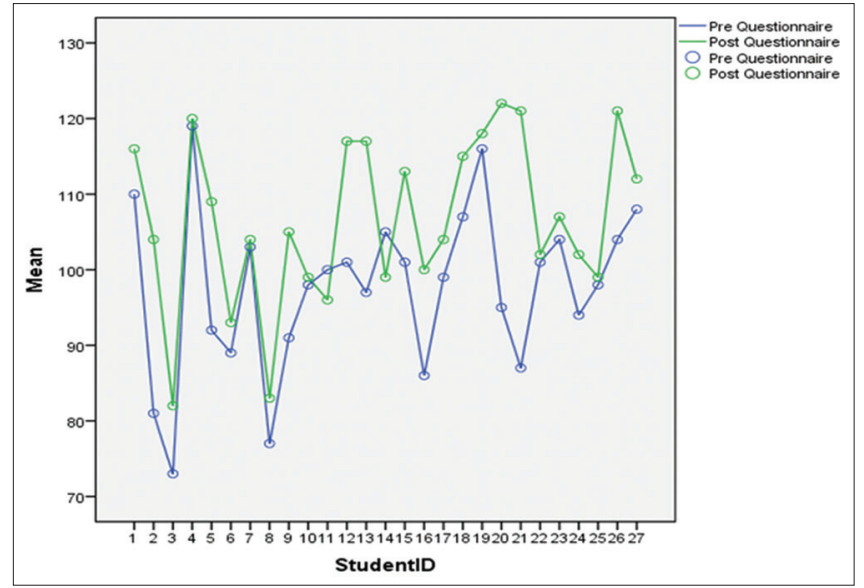

Figure 3: Line graph illustrating pre and post scores for motivation questionnaire

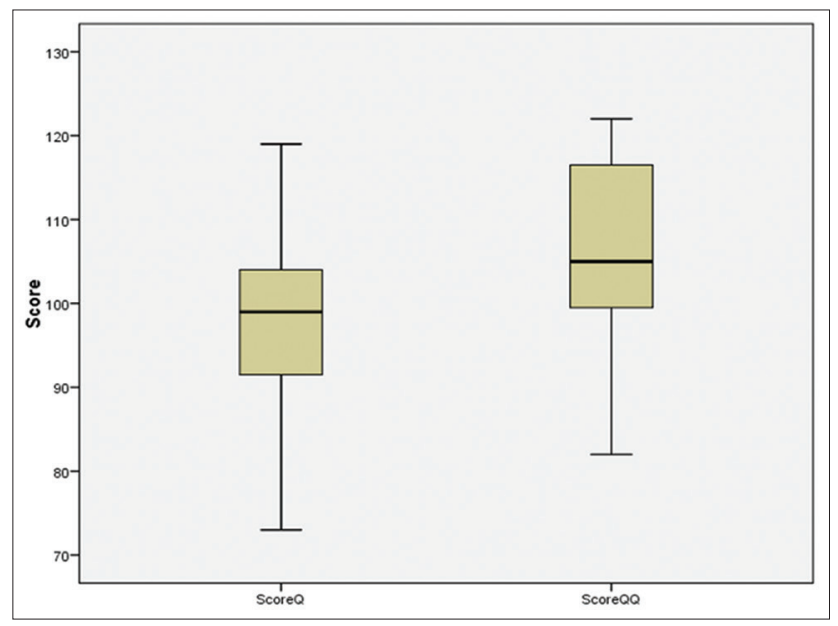

Figure 4: Box and whisker plot for pre-questionnaire (Score $Q$ ) and postquestionnaire (Score QQ). also determined for the pre- and post-questionnaire to determine if there was a difference in these indicators before the use of the intervention as compared to after the use of the intervention.

The mean score of 97.63 and 106.67 was obtained for the pre- and post-questionnaire, respectively (Table 3 ). The mean scores for motivation were high before the intervention; however, the difference in the mean scores indicated that the intervention still impacted motivation. The level of skewness also supported this finding as the post-questionnaire skew was more negative indicating that of the values lie to the right of the mean, confirming an increase in motivation scores.

Using the raw data scores a line graph (Figure 3) were constructed to illustrate any differences in the pre- and postquestionnaire scores. From the graph, it was seen that 24 out of 27 students scored higher in the post-intervention questionnaire compared to the pre-intervention questionnaire.

A box and whisker plot (Figure 4) was generated to show the distribution of the data and identify any patterns in the quantitative data. It was observed that the box plot for the post-questionnaire was positioned much higher than the box plot for the pre-questionnaire. This indicates an increase in overall motivation scores after the use of the intervention. From Figure 4, it is evident that the middle quartile/median scores increased after the intervention and this is confirmed when viewing the quartile values illustrated in Table 4 . The middle quartile/median for the pre-questionnaire was found to be equivalent to the lower quartile value for the post-questionnaire with a value of 99 . It can be seen generally that the data are well distributed across a large range with the exception of the upper quartile for the post-questionnaire scores. The short upper whisker illustrates that student motivation is very similar for the most positive quartile group (Table 4).

Frequency histograms were plotted for the data (Figure 5) to better understand the distribution of the data. It was found that the data for both the pre- and post-questionnaire were normally distributed; however, the post-questionnaire data were skewed to the left indicating a higher motivation of students following the intervention.

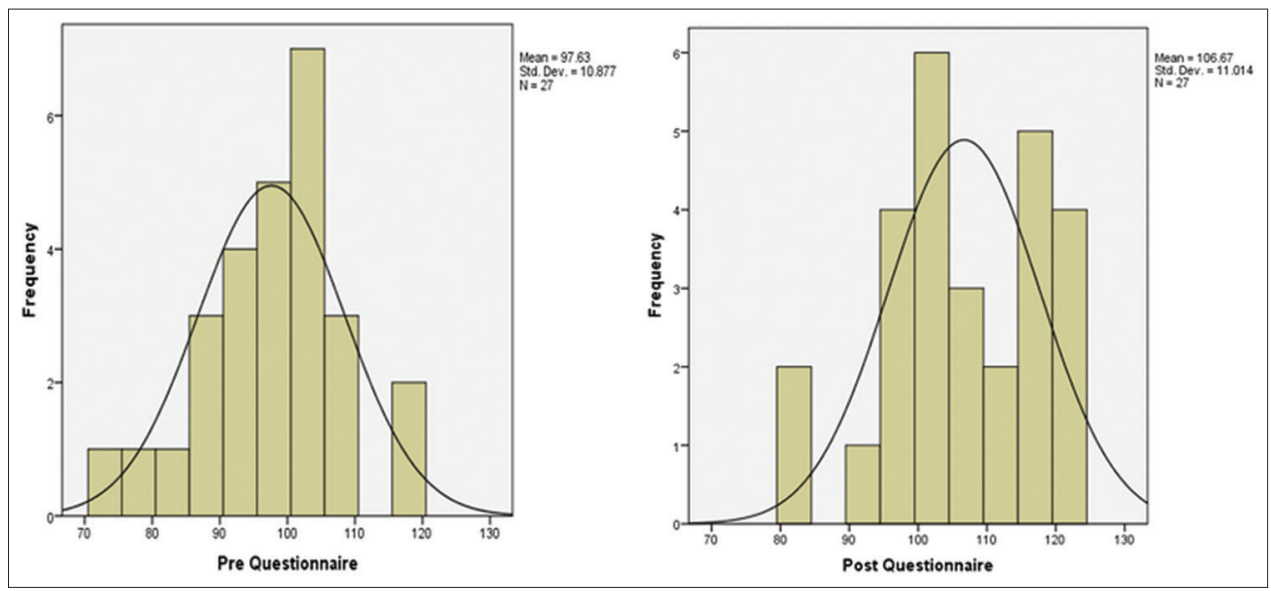

Figure 5: Histograms illustrating pre- and post-questionnaire frequency distributions 


\begin{tabular}{|c|c|c|c|c|c|c|c|c|}
\hline \multirow{2}{*}{$\begin{array}{l}\text { Group of Motivation } \\
\text { Questionnaire Score } \\
\text { (i.e. pre or post) }\end{array}$} & \multirow{2}{*}{$\begin{array}{c}\mathbf{n} \\
\text { Statistic }\end{array}$} & \multirow{2}{*}{$\begin{array}{c}\text { Range } \\
\text { Statistic }\end{array}$} & \multirow{2}{*}{$\begin{array}{c}\text { Minimum } \\
\text { Statistic }\end{array}$} & \multirow{2}{*}{$\begin{array}{c}\text { Maximum } \\
\text { Statistic }\end{array}$} & \multirow{2}{*}{$\begin{array}{c}\text { Mean } \\
\text { Statistic }\end{array}$} & \multirow{2}{*}{$\begin{array}{c}\text { Std. deviation } \\
\text { Statistic }\end{array}$} & \multicolumn{2}{|c|}{ Skewness } \\
\hline & & & & & & & Statistic & Std. error \\
\hline Score Q (Pre-score) & 27 & 46 & 73 & 119 & 97.63 & 10.877 & -0.364 & 0.448 \\
\hline Score QQ (post-score) & 27 & 40 & 82 & 122 & 106.67 & 11.014 & -0.516 & 0.448 \\
\hline Valid N (listwise) & 27 & & & & & & & \\
\hline
\end{tabular}

\begin{tabular}{lcc}
\hline $\begin{array}{l}\text { Table 4: Quartiles values for pre- and post-questionnaire } \\
\text { data }\end{array}$ & & \\
\hline $\begin{array}{l}\text { Details about Quartiles on Motivation } \\
\text { Questionnaire (pre-Q and post-QQ) }\end{array}$ & Score Q & Score QQ \\
\hline $\mathrm{n}$ & & \\
Valid & 27 & 27 \\
Missing & 0 & 0 \\
Percentiles & & \\
25 & 91.00 & 99.00 \\
50 & 99.00 & 105.00 \\
75 & 104.00 & 117.00 \\
\hline
\end{tabular}

\begin{tabular}{|c|c|c|c|c|}
\hline $\begin{array}{l}\text { Group of } \\
\text { Motivational } \\
\text { Scores }\end{array}$ & Mean & n & Std. deviation & Std. error mean \\
\hline \multicolumn{5}{|l|}{ Pair 1} \\
\hline Pre & 97.63 & 27 & 10.877 & 2.093 \\
\hline Post & 106.67 & 27 & 11.014 & 2.120 \\
\hline
\end{tabular}

$\begin{aligned} & \text { Table 6: T-test for pre- and post-questionnaire } \\
& \text { scores - paired samples correlations }\end{aligned}$
\begin{tabular}{lccc}
\hline Groups & $\mathbf{n}$ & Correlation & Sig. \\
\hline $\begin{array}{l}\text { Pair 1 } \\
\text { Pre and post }\end{array}$ & 27 & 0.617 & \\
\hline
\end{tabular}

To compare the means of the scores before and after the intervention of the same participant, a t-test was used. The hypotheses tested were as follows:

- The null hypothesis:

$\mathrm{H}_{0}$ : There is no difference in pre- and post-questionnaire scores of students' before or after the intervention that is $\mu_{1=} \mu_{2}$

- The alternative hypothesis:

$\mathrm{H}_{1}$ : There is a significant difference in students' pre- and post-questionnaire scores after the intervention that is $\mu_{1} \neq \mu_{2}$

The results from the t-test analysis are displayed in Tables 5-7.

The t-test was conducted at a confidence level of $95 \%$, with $26^{\circ}$ of freedom. The null hypothesis is rejected, since $\rho<0.05$ $(\rho=0.000)$ (Table 7). There is, therefore, evidence $(t=-4.901$, $\rho=0.000$ ) that there was a significant difference in the pre- and post-test scores for motivation. In this experiment, the $95 \%$ confidence interval ranged from -12.827 to -5.247 (Table 7).

The sample size was small which threatened the validity of the results of the t-test. Hence, a Kolmogorov-Smirnov test was conducted to ensure that the data followed a normal distribution and so strengthen the validity of the t-test. Data from this test are illustrated in Table 7. For this analysis to be valid the null hypothesis must be accepted (i.e., a non-significant result where $\rho>0.05$ ). From the results in Table 8 , it can be seen that all the variables assessed followed a normal distribution and hence one of the criteria for the validity of the t-test was met.

To further evaluate the data, the Wilcoxon Signed-rank Test was conducted to compare the means of the scores before and after the intervention as this is suitable for data which is $<30$. The hypotheses tested were as follows:

- $\quad$ The null hypothesis

$\mathrm{H}_{0}$ : There is no difference in pre- and post-questionnaire scores of students' before or after the intervention that is $\mu_{1=} \mu_{2}$

- The alternative hypothesis:

$\mathrm{H}_{1}$ : There is a significant difference in students' pre- and post-questionnaire scores after the intervention that is $\mu_{1} \neq \mu_{2}$

The results from the Wilcoxon Signed-rank Test are displayed in Tables 9 and 10.

The null hypothesis is rejected, since $\rho<0.05(\rho=0.000)$ (Table 10). There is, therefore, evidence that there was a significant difference between the pre-test and post-test scores for motivation. This mirrors the findings of the t-test conducted.

\section{Research Question Two}

What is the impact of "the flipped classroom" model on academic performance of students after they have been exposed to a unit of work on rates of chemical reactions?

Base scores and post-test scores were tabulated, and a bar chart and box and whisker chart plotted to visually compare the scores. The results of the statistical analysis for mean, standard deviation, range, minimum and maximum, and skewness for the base score and post-test are displayed in Table 11. This data were used to determine if there was a difference in academic performance before the use of the intervention and after the use of the intervention.

The data presented in Table 11 represents 25 students as two students were absent for one of the assessments. There was an 


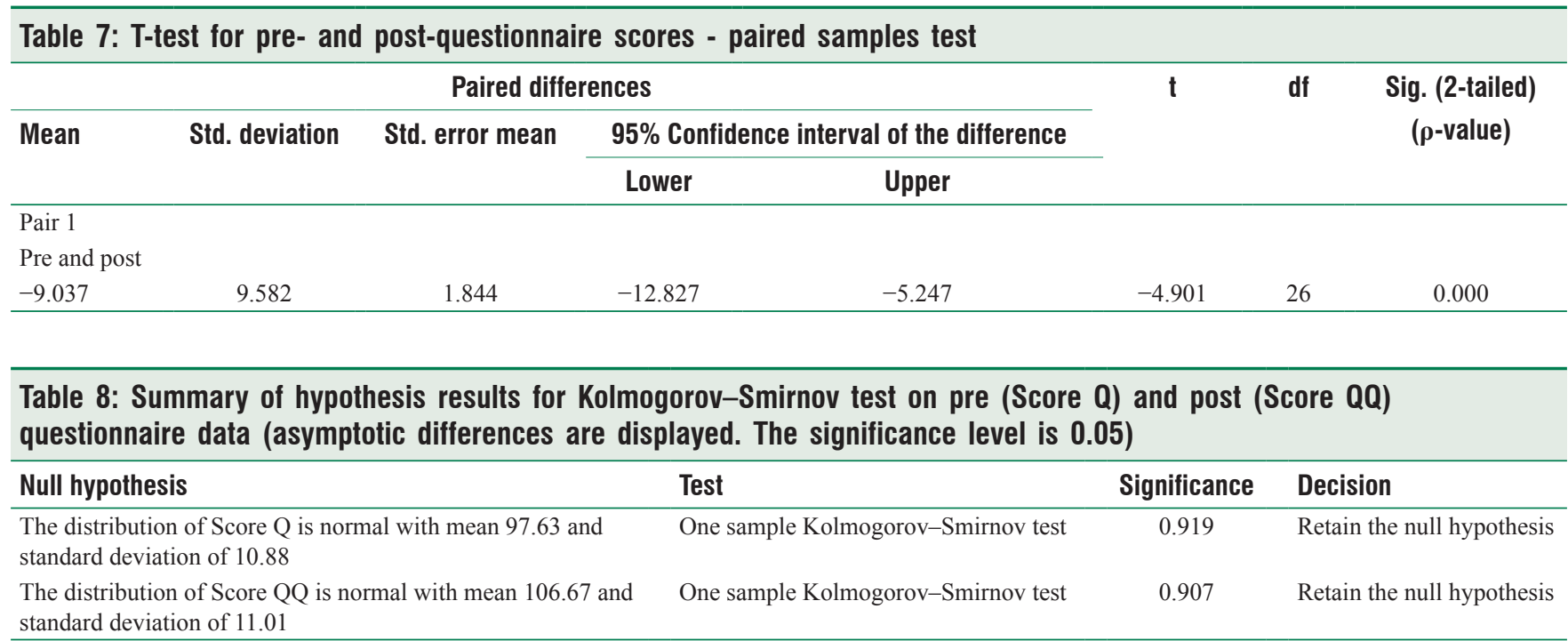

\begin{tabular}{|c|c|c|c|}
\hline $\begin{array}{l}\text { Ranks for Pre-Post } \\
\text { Questionnaires }\end{array}$ & $\mathrm{n}$ & Mean rank & Sum of ranks \\
\hline \multicolumn{4}{|l|}{ Pre - Post } \\
\hline Negative ranks & $25^{\mathrm{a}}$ & 14.24 & 356.00 \\
\hline Positive ranks & $2^{\mathrm{b}}$ & 11.00 & 22.00 \\
\hline Ties & $0^{\mathrm{c}}$ & & \\
\hline Total & 27 & & \\
\hline
\end{tabular}

Table 10: Wilcoxon Signed-rank test for pre- and post-questionnaire scores - paired samples test

\begin{tabular}{lc}
\hline Statistics & Pre - Post \\
\hline$Z$ & $-4.017^{\mathrm{b}}$ \\
Asymp. Sig. (2-tailed) & 0.000 \\
\hline${ }^{\mathrm{a}}$ Wilcoxon signed-rank test, ${ }^{\mathrm{b}}$ Based on positive ranks
\end{tabular}

increase in the mean between the base score and post-test score by approximately four points. The range of the scores was seen to narrow marginally by six indicating a small decrease in the difference between the highest and lowest marks for the posttest score when compared to the base score. Standard deviation values also illustrated this trend as there was less deviation in the post-test scores compared to the base scores. The test for skewness produced the most observable difference between the base score and the post-test score. The base score was positively skewed $(0.168)$ while the post-test scores were negatively skewed $(-0.295)$. This indicated that the base score values had a greater number of scores below the meanwhile the post-test scores have a greater number of scores above the mean. This observation is valuable as it indicated some improvement in academic performance following the intervention.

A box and whisker plot (Figure 6) was generated to show the distribution of the data and identify any patterns in the

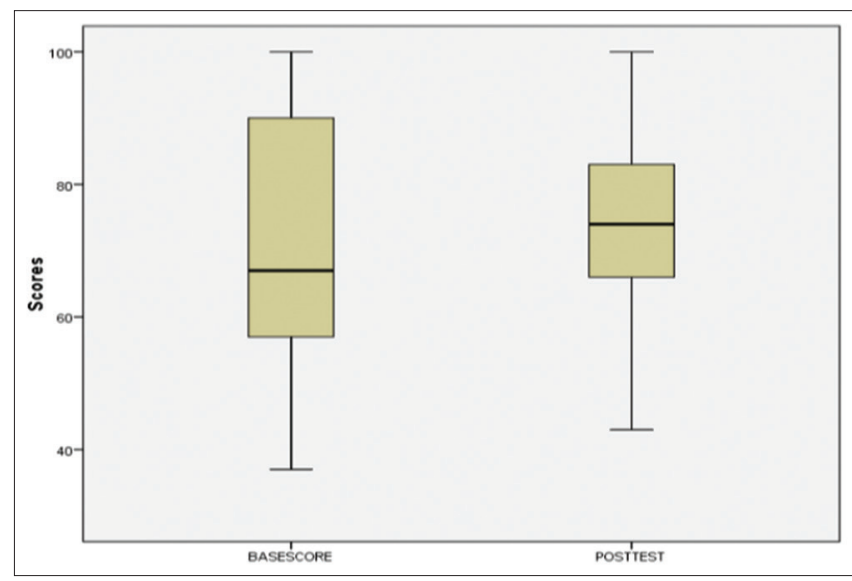

Figure 6: Box and whisker plot for base score and post-test score

quantitative data. It was observed that the box plot for the post-test was comparatively shorter than the pre-test plot. This indicated that there was a greater similarity in terms of student performance in the post-test compared to the pre-test which was more widely distributed. From Table 12, it can be seen that the middle quartile/ median score was higher in the post-test (74) compared to the pre-test value (67); however, the upper quartile score was higher in the base score (90) compared to the post-test (83).

Frequency histograms were plotted for the data (Figure 7) to better understand the distribution of the data. It was found that the data for both the base score and post-test score were normally distributed with the spread of the data similar below the mean for both data sets. There were more values above the mean for the base score compared to the post-test score.

When analyzing the bar chart (Figure 8), it was seen that 13 students improved their test scores, 2 students did not change scores, and 10 students declined in performance.

In order to compare the means of the scores before and after the intervention on the same participant a paired, non-directional 


\begin{tabular}{|c|c|c|c|c|c|c|c|c|}
\hline \multirow{2}{*}{$\begin{array}{l}\text { Group of } \\
\text { Academic } \\
\text { Scores }\end{array}$} & \multirow{2}{*}{$\frac{\mathbf{n}}{\text { Statistic }}$} & \multirow{2}{*}{$\begin{array}{c}\text { Range } \\
\text { Statistic }\end{array}$} & \multirow{2}{*}{$\begin{array}{c}\text { Minimum } \\
\text { Statistic }\end{array}$} & \multirow{2}{*}{$\begin{array}{c}\text { Maximum } \\
\text { Statistic }\end{array}$} & \multirow{2}{*}{$\frac{\text { Mean }}{\text { Statistic }}$} & \multirow{2}{*}{$\begin{array}{c}\text { Std. deviation } \\
\text { Statistic }\end{array}$} & \multicolumn{2}{|c|}{ Skewness } \\
\hline & & & & & & & Statistic & Std. error \\
\hline BASE SCORE & 26 & 63 & 37 & 100 & 70.00 & 19.291 & 0.168 & 0.456 \\
\hline POST-TEST & 26 & 57 & 43 & 100 & 73.92 & 13.014 & -0.295 & 0.456 \\
\hline Valid N (listwise) & 25 & & & & & & & \\
\hline
\end{tabular}
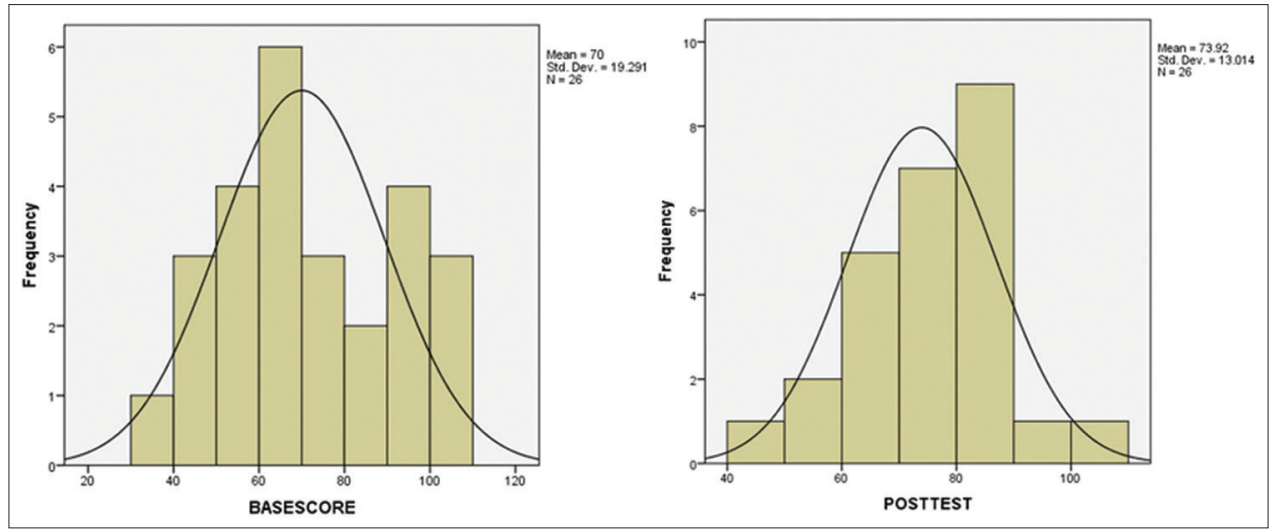

Figure 7: Histograms illustrating base score and post-test score frequency distributions

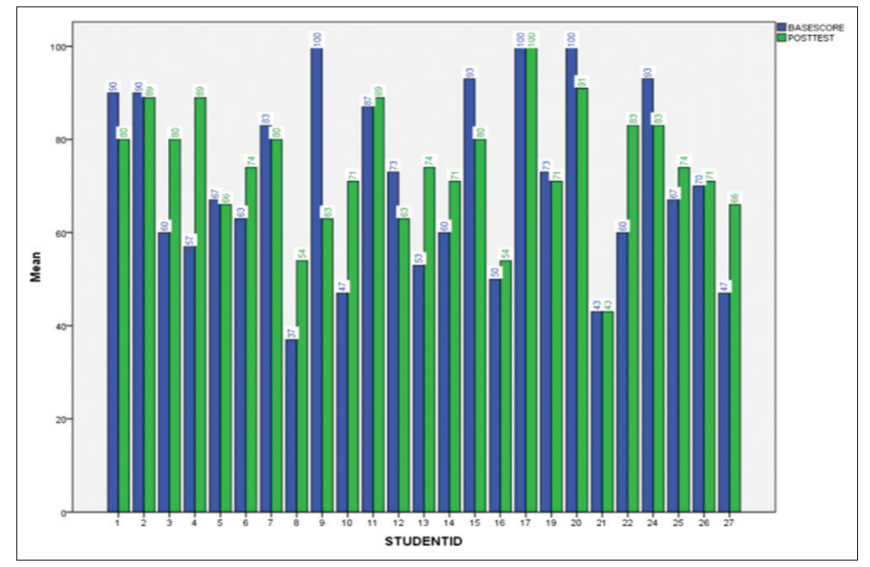

Figure 8: Bar chart illustrating base scores and post-test scores for students

t-test was used. The hypotheses tested were as follows:

- The null hypothesis

$\mathrm{H}_{0}$ : There is no difference in the academic performance of students before or after the intervention that is $\mu_{1=} \mu_{2}$

- The alternative hypothesis

$\mathrm{H}_{1}$ : There is a significant difference in students' academic scores after the intervention that is $\mu_{1} \neq \mu_{2}$

The results from the t-test analysis are displayed in Tables 13-15.

The t-test was conducted at a confidence level of $95 \%$, with $24^{\circ}$ of freedom. The null hypothesis is accepted, since $\rho$ $>0.05(\rho=0.217)$ (Table 15). This result $(t=-1.269, \rho$ $=0.217$ ) indicated that the teaching intervention did not improve academic performance. In this experiment, the $95 \%$ confidence interval ranged from -10.087 to 2.407 . While this value indicated a large difference in scores of approximately $12 \%$, the means of the two scores were determined to be statistically similar.

The sample size was small which threatened the validity of the results of the t-test. Hence, a Kolmogorov-Smirnov test was conducted to ensure that the data followed a normal distribution and so strengthen the validity of the t-test. This was done using a Kolomogorov-Smirnov test. Data from this test are illustrated in Table 16. For this analysis to be valid the null hypothesis must be accepted, i.e., a non-significant result where $\rho>0.05$.

From the results in Table 16, it can be seen that all the variables assessed followed a normal distribution and hence one criterion for the validity of the t-test is met.

To further evaluate the data, the Wilcoxon Signed-rank Test was conducted to compare the means of the scores before and after the intervention as this is suitable for data which is $<30$. The hypotheses tested were as follows:

- The null hypothesis.

$\mathrm{H}_{0}$ : There is no difference in base and post-test scores of students' before or after the intervention that is $\mu_{1=} \mu_{2}$

- The alternative hypothesis.

$\mathrm{H}_{1}$ : There is a significant difference in students' base and post-test scores after the intervention that is $\mu_{1} \neq \mu_{2}$

The results from the Wilcoxon Signed-rank Test are displayed in Tables 17 and 18 .

The null hypothesis is retained, since $\rho>0.05(\rho=0.186)$ (Table 18). There is no difference between the pre-test and post-test scores for base and post-test scores. This mirrors the findings of the t-test conducted. 


\section{Research Question Three}

What are students' perceptions of the intervention/flipped classroom?

The journals were coded by looking for statements that demonstrated students' positive, negative, or neutral feelings and experiences with a flipped classroom, Table 19. Code counting was also undertaken to determine students' perception of the intervention.

\begin{tabular}{lcc}
\hline \multicolumn{2}{l}{ Table 12: Quartiles for base score and post-test score } \\
\hline $\begin{array}{l}\text { Details About Quartiles } \\
\text { on Academic Tests }\end{array}$ & Base score & Post-test \\
\hline $\mathrm{n}$ & & \\
Valid & 26 & 26 \\
Missing & 1 & 1 \\
Percentiles & & \\
25 & 56.00 & 65.25 \\
50 & 67.00 & 74.00 \\
75 & 90.00 & 83.00 \\
\hline
\end{tabular}

\begin{tabular}{|c|c|c|c|c|}
\hline $\begin{array}{l}\text { Group of } \\
\text { Academic } \\
\text { Scores }\end{array}$ & Mean & $\mathrm{n}$ & Std. deviation & Std. error mean \\
\hline \multicolumn{5}{|l|}{ Pair 1} \\
\hline $\begin{array}{l}\text { BASE } \\
\text { SCORE }\end{array}$ & 70.52 & 25 & 19.502 & 3.900 \\
\hline POST-TEST & 74.36 & 25 & 13.086 & 2.617 \\
\hline
\end{tabular}

\begin{tabular}{|c|c|c|c|}
\hline $\begin{array}{l}\text { Group of Paired Samples } \\
\text { of Academic Scores }\end{array}$ & $\mathrm{n}$ & Correlation & Sig. \\
\hline \multicolumn{4}{|l|}{ Pair 1} \\
\hline Base score and post-test & 25 & 0.632 & 0.001 \\
\hline
\end{tabular}

Using journal entries, the students were able to indicate how they perceived the intervention of a flipped classroom, in particular, the flipped classroom's requirement of completing lectures at home rather than in class. The vast majority of students preferred having the work available to them at home.

Many students indicated that they enjoyed the use of the technology at home. Technology, however, posed a problem for several of the students who displayed a negative perception of the intervention. Two students indicated that they had no preference in terms of the typical approach of in-class work versus the use of the intervention. On the assessment of the journal entries, it can be concluded that the "flipped classroom" model was generally well received by students.

\section{CONCLUSION}

The flipped classroom model was found to positively and significantly impact on student motivation while having no significant effect on academic achievement. Students' perception of the flipped classroom was generally positive.

The conclusions drawn based on the improvement of student motivation after the intervention are consistent with the current findings on the influence of student-centered active learning and the flipped classroom model on student motivation (Knewton, 2012).

In contrast to the present literature, this study did not find a significant result with regard to the flipped classroom model and academic achievement. The base score utilized as the pre-test value and the post-test results was not significantly different. However the academic literature indicated improvements in terms of academic achievement (e.g., Kirch, 2012; Fulton, 2012; and Green, 2012). This disparity between the findings and the research literature may have been due to the constraints faced in this study. Students faced problems accessing the materials. This hampered the study, and various methods were attempted in terms of delivery of the material to circumvent this issue. Methods included providing the lecture materials through email, flash drives, and links. However, these were also not ideal as some students had problems accessing

Table 15: T-test for base score and post-test scores - paired samples test

\begin{tabular}{|c|c|c|c|c|c|c|c|c|}
\hline \multirow{3}{*}{$\begin{array}{l}\text { Group of Paired } \\
\text { Samples of } \\
\text { Academic Scores }\end{array}$} & \multicolumn{5}{|c|}{ Paired differences } & \multirow[t]{3}{*}{$t$} & \multirow[t]{3}{*}{ df } & \multirow[t]{3}{*}{ Sig. (2-tailed) ( $\rho$-value) } \\
\hline & \multirow[t]{2}{*}{ Mean } & \multirow[t]{2}{*}{ Std. dev. } & \multirow[t]{2}{*}{ Std. error mean } & \multicolumn{2}{|c|}{$\begin{array}{l}\text { 95\% Confidence interval of the } \\
\text { difference }\end{array}$} & & & \\
\hline & & & & Lower & Upper & & & \\
\hline \multicolumn{9}{|l|}{ Pair 1} \\
\hline Base score - post-test & -3.840 & 15.135 & 3.027 & -10.087 & 2.407 & -1.269 & 24 & 0.217 \\
\hline
\end{tabular}

Table 16: Kolmogorov-Smirnov test for determination of t-test validity

\begin{tabular}{llcl}
\hline Null hypothesis & Test & Significance & Decision \\
\hline $\begin{array}{l}\text { The distribution of BASE SCORE is normal with mean } 70.00 \text { and } \\
\text { standard deviation of } 19.29\end{array}$ & One sample Kolmogorov-Smirnov test & 0.841 & Retain the null hypothesis \\
$\begin{array}{l}\text { The distribution of POST-TEST is normal with mean } 73.92 \text { and } \\
\text { standard deviation of 13.01 }\end{array}$ & One sample Kolmogorov-Smirnov test & 0.94 & Retain the null hypothesis \\
\hline $\begin{array}{l}\text { Asymptotic significances are displayed. The significance level is } 0.05 \\
\text { Asym }\end{array}$ &
\end{tabular}


their email; moreover, students also did not regularly bring flash drives for the transfer of materials. This challenge was related to the governmentally issued laptops which had been provided to the students 3 years earlier. Several students indicated that many of the problems viewing the resources originated directly from the inability to update the software on the computers due to administrative password restrictions, and to the fact that the laptops had not been regularly maintained.

Another issue was students completing the lectures at home. Some students, even though they had access to the materials did not complete the lectures at home.

These factors were all setbacks as at times work had to be recovered in the classroom. This may have contributed to the finding of no significant difference in academic performance after the use of the intervention as students was not able to make full use of the intervention.

Student perception of the flipped classroom model was consistent with the literature (Johnson, 2013) where students generally enjoyed learning using the intervention.

\begin{tabular}{|c|c|c|c|}
\hline & $\mathbf{n}$ & Mean rank & Sum of ranks \\
\hline \multicolumn{4}{|l|}{ BASE } \\
\hline Negative ranks & $13^{\mathrm{a}}$ & 13.96 & 181.50 \\
\hline Positive ranks & $10^{\mathrm{b}}$ & 9.45 & 94.50 \\
\hline Ties & $2^{\mathrm{c}}$ & & \\
\hline Total & 25 & & \\
\hline
\end{tabular}

\begin{tabular}{|c|c|}
\hline \multicolumn{2}{|c|}{$\begin{array}{l}\text { Table 18: Wilcoxon signed-rank test for base and } \\
\text { post-test scores - paired samples test }\end{array}$} \\
\hline Statistics & BASE SCORE - POST-TEST \\
\hline $\mathrm{Z}$ & $-1.324^{\mathrm{b}}$ \\
\hline Asymp. Sig. (2-tailed) & 0.186 \\
\hline
\end{tabular}

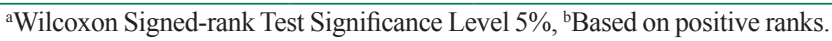

\section{Implications}

The flipped classroom model has the potential to change the method of delivery of teachers in Trinidad and Tobago. The ability to deliver classes asynchronously is very valuable as time constraints are a common issue among many teachers due to the sheer volume of the curriculum, and the many cocurricular school activities carded during the academic year of the school in which the study was located. Time lost during class time can be recovered using asynchronous delivery of the material.

With the move toward student-centered teaching models around the world, the flipped classroom model is a viable new student-centered model which can be employed by teachers and allow students to be more responsible for their own learning. This will free classroom time for more personalized instruction as needed by students.

The time to assist students is just one possible benefit of this model to students. Students can also benefit from the fact that they are able to complete the lectures at their own pace and are able to review as many times as they need to become comfortable with the material.

\section{Recommendations}

While there was a significant improvement in motivation levels, academic achievement was not significantly improved. The "flipped classroom" model should be promoted in schools in Trinidad and Tobago; however, it should not be the only method of teaching utilized. This method takes time to prepare and is not suitable for all students due to the constraints mentioned.

This study would have been better executed through the provision of the materials to the students in DVD or CD form. This could have eliminated several of the issues concerning student access to the materials. While this method was well received by most students, some indicated a preference for in-class lectures. This leads me to believe that my students would have benefitted more from a blended teaching approach composed of a combination of asynchronous and synchronous lectures.

\begin{tabular}{lcll}
\hline Table 19: Journal analysis & & \\
\hline Statements/codes & $\begin{array}{c}\text { Number times code } \\
\text { appeared }\end{array}$ & $\begin{array}{l}\text { Examples of this code from students" } \\
\text { journals }\end{array}$ & Analysis of code \\
\hline Positive & 43 & $\begin{array}{l}\text { "prefer viewing at home" } \\
\text { "relaxing to do stuff at home" } \\
\text { "doing work at home great" } \\
\text { "this way of teaching has helped" } \\
\text { "enjoyed PowerPoint, videos" } \\
\text { "understand more in class" } \\
\text { "prefer class" }\end{array}$ & $\begin{array}{l}\text { Greater number of students are receptive to the intervention } \\
\text { and the idea of working from home }\end{array}$ \\
"prefer school" & Some students prefer learning in the classroom setting \\
"trouble accessing" & "don't know what I prefer" \\
"neutral about doing work at home" & & These students have no preference \\
\hline
\end{tabular}




\section{REFERENCES}

Akbaş, A., \& Kaan, A. (2007). Affective factors that influence chemistry achievement (motivation and anxiety) and the power of these factors to predict chemistry achievement. Journal of Turkish Science Education, $4(1), 10-20$.

Altermatt, B. (2014). Threats to Internal Validity for Within-subjects Designs. Available from: http://www.vault.hanover.edu/ altermattw/courses/220/ readings/Within subjects.pdf. [Last retrieved on 2018 Sep 26].

Bandura, A. (1997). Self-Efficacy: The Exercise of Control. New York, NY: Freeman.

Barlia, L. (1999). High School Students' Motivation to Engage in Conceptual Change-learning in Science (Unpublished Doctoral Dissertation, Ohio State University, USA.)

Britner, S.L., \& Pajares, F. (2001). Self-efficacy beliefs, motivation, race, and gender in middle school science. Journal of Women and Minorities in Science and Engineering, 7, 271-285.

Britner, S.L., \& Pajares, P. (2006). Sources of science self-efficacy beliefs of middle school students. Journal of Research in Science Teaching, 43(5), 485-499.

Brophy, J. (1998). Motivating Students to Learn. New York: McGraw-Hill.

Cavas, B. (2011). Factors affecting the motivation of Turkish primary students for science learning. Science Education International, 22(1), $31-42$.

Creswell, J.W., \& Clark, D.P. (2007). Designing and Conducting Mixed Methods Research. Thousand Oaks, CA: Sage Publications, Inc.

Culp, K., Hawkins, J., \& Honey, M. (1999). Review Paper on Educational Technology Research and Development. New York: Education Development Center, Center for Children and Technology.

Franciszkowicz, M. (2008). Video-based additional instruction. Journal of the Research Center for Educational Technology, 4(2), 5-14.

Fulton, K. (2012). Inside the flipped classroom. The Journal. Available from: http://www.thejournal.com/articles/2012/04/11/the-flipped-classroom. aspx. [Last retrieved on 2018 Sep 26]

Glynn, S.M., Brickman, P., Armstrong, N., \& Taasoobshirazi, G. (2011). Science motivation questionnaire II: Validation with science majors and nonscience majors. Journal of Research in Science Teaching, 48(10), $1159-1176$.

Green, G. (2012). The Flipped Classroom and School Approach: Clintondale High School. Paper Presented at The Annual Building Learning Communities Education Conference, Boston, MA.

Haury, D., \& Rillero, P. (1994). Perspectives of Hands-on Science Teaching. Retrieved from the ERIC Clearinghouse for Science, Mathematics and Environmental Education. (ED372926).

Johnson, G.B. (2013). Students Perceptions of the Flipped Classroom (Unpublished Master's Dissertation, University of British Columbia, Canada.).

Jonassen, D.H. (1993). Thinking technology: Context is everything. Educational Technology, 31(6), 35-37.

King, A. (1993). From sage on the stage to guide on the side. College Teaching, 41(1), 30-35.

Kirch, C. (2012). Flipping with Kirch. Available from: http://www. flippingwithkirch.blogspot.ca/p/2011-2012-test-score-data.html. [Last retrieved on 2018 Sep 26].
Knewton. (2012). The Flipped Classroom Infographic: A New Method of Teaching is Turning the Traditional Classroom on its Head. Available from: http://www.knewton.com/flipped-classroom/. [Last retrieved on 2018 Sep 26].

Meyers, C., \& Jones, T.B. (1993). Promoting Active Learning: Strategies for the College Classroom. San Francisco, CA: Jossey Bass Pub.

Nugent, G.C., Soh, L., \& Samal, A. (2006). Development and validation of learning objects. Journal of Educational Technology Systems, 34, 271-281.

O’Neil, K., Kelly, T., \& Bone, S. (2012). We turned learning on its ear: Flipping the developmental classroom. In: Amiel, T., \& Wilson, B., (Eds.), Proceedings of World Conference on Educational Multimedia, Hypermedia and Telecommunications. Chesapeake, VA: AACE. pp. 2752-2756.

Prosser, M., \& Trigwell, K. (1998). Teaching for Learning in Higher Education. Buckingham, UK: Open University Press.

Ramsden, P. (1992). Learning to Teach in Higher Education. London, UK: Routledge.

Rhodes, L.K., \& Bellamy, T. (1999). Choices and consequences in the reform of teacher education. Journal of Teacher Education, 50(1), 17-26.

Roach, J. (2006). Using screen capture technology to develop on-line course material. In: Crawford, C., Davis, N., Price, J., Weber, R., \& Willis, D., (Eds.), Proceedings of Society for Information Technology and Teacher Education International Conference. Chesapeake, VA: AACE. pp. 519-520.

Ross, K. (2005). Module 3: Sample design for educational survey research. Paris, France: International Institute for Education Planning/UNESCO.

Salta, K., \& Koulougliotis, D. (2012). Students' motivation to learn chemistry: The Greek case. Proceedings of the $1^{\text {st }}$ International Conference New Perspectives in Science Education. Florence, Italy. pp. 8-9.

Sandholtz, J.H., Ringstaff, C., \& Dwyer, D.C. (1997). Teaching with Technology: Creating Student-centered Classrooms. New York: Teachers College Press.

Sezer, R. (2010). Pulling out all the stops. Education, 130(3), 416-423.

Shadish, W.R., Cook, T.D., \& Campbell, D.T. (2002). Experimental and Quasi-experimental Designs for Generalized Causal Inference. Boston, MA: Houghton Mifflin.

Shell, D.F., Colvin, C., \& Bruning, R.H. (1995). Self-efficacy, attribution, and outcome expectancy mechanisms in reading and writing achievement: Grade-level and achievement-level differences. Journal of Educational Psychology, 87(3), 386-398.

Singh, K., Granville, M., \& Dika, S. (2002). Mathematics and science achievement: Effects of motivation, interest, and academic engagement. The Journal of Educational Research, 95(6), 323-332.

Slavin, R. (2007). Educational Research in the Age of Accountability. Boston, MA: Allyn \& Bacon.

Tucker, B. (2012). The flipped classroom. Education Next, 12(1), 82-83.

Tucker, C.M., Zayco, R.A., \& Herman, K.C. (2002). Teacher and child variables as predictors of academic engagement among low-income African American children. Psychology in the Schools, 39(4), 477-488.

Usher, A., \& Kober, N. (2012). What nontraditional approaches can motivate unenthusiastic students? Student Motivation: An Overlooked Piece of School Reform (Paper 6). Washington, DC: Center on Education Policy, the George Washington University. 